\title{
Internal marketing policies and procedures at Prince Sattam Bin Abdulaziz University and the extent of workers' satisfaction
}

\author{
Nabil Mohemmed Al-Hazmi ${ }^{\mathbf{a}, \mathbf{b}^{*}}$
}

${ }^{a}$ Associate Professor of Marketing-Department of Marketing, College of Business Administration, Prince Sattam bin Abdulaziz University-Kingdom of Saudi Arabia

${ }^{b}$ Associate Professor of Marketing-College of Administrative Sciences- Taiz University, Yemen

\section{CH R O N I C L E}

\section{Article history:}

Received: November 11, 2019

Received in revised format: November 302019

Accepted: December 18, 2019

Available online:

December 20, 2019

Keywords:

Internal Marketing

University

Staff Satisfaction

Performance

\section{A B S T R A C T}

\begin{abstract}
The main objective of this study was to determine the main policies and procedures related to internal marketing applied at Prince Sattam bin Abdulaziz University and the degree of employees' satisfaction. The researcher relied on the descriptive analytical method in conducting this study. The study reached several conclusions. Most notably; most of the internal marketing policies and procedures applied at Prince Sattam bin Abdul Aziz University are conducted moderately. The results of the study also showed a statistically significant relationship between the level of the application of marketing policies and procedures at Prince Sattam bin Abdul Aziz University and the level of employees' satisfaction with the application of these policies and procedures. The study concluded to provide a set of recommendations necessary to activate the application of internal marketing policies and procedures at Prince Sattam bin Abdul Aziz University to achieve its employees' satisfaction.
\end{abstract}

C) 2020 by the authors; licensee Growing Science, Canada

\section{Introduction}

Internal marketing is a very important activity in service institutions, especially educational institutions since the characteristics of educational services distinguish them from other products, the most prominent feature is the correlation between service providers and customers (Hammed, 2015). Thus, the success of marketing these services and providing them with high quality to customers depend on the efficiency and skills of service providers working in different educational institutions and their satisfaction with various dimensions of internal marketing followed by these institutions (Hadad, 2018). Marketing has traditionally focused on exchanges between the organization and customers, but the role played by organization's staff in determining the level of quality and customers' satisfaction with the marketing offer has drawn attention to another forms of exchange. This can be done between the organization and its staff. Because of the special characteristics of services, traditional methods of external marketing practices face with limited effectiveness when applied in services relative to physical goods. The performance of service workers represents the product purchased by the external customer and one of the main means used by the organization to achieve market excellence. A modern marketing concept for employees within the organization has emerged as internal marketing (Alkhashab, 2009; William, 1990). The concept of internal marketing emerged in the early 1950 s by Japanese quality managers and viewed the activities performed by employees as internal products. The organization should focus on the employees' interests and try to satisfy them through their activities to ensure a highly qualified workforce as well as satisfying the external customer (Almaaghrabi, 2014). The concept of internal marketing appeared in service organizations, and the main application was how to identify the training needs and solve the marketing services problems in many service institutions such as banks, hospitals, hotels, public transport services companies, etc. (Berry, 1981, Grönroos,

* Corresponding author.

E-mail address: alhazmi1976@gmail.com (N. M. Al-Hazmi) 
1990). Internal marketing considers all the organization employees to be internal customers who must achieve the goals of the organization. The functions of individuals contribute to this by responding to the internal audience. Each is directly or indirectly related to the end consumer or competitive advantage (Harrell \& Fors, 1995; Thabit, 2015, 2016). Internal marketing refers to the design of policies and programs directed to the organization's staff (internal customers) in order to achieve high levels of satisfaction to them, which in turn can lead to improve the quality of service provided to external customers. This means that identifying the importance of the role of employees in marketing the service requires management to consider them as representing the first market of the organization and their functions represent internal products which must be designed and developed in accordance with their needs and desires and thus increase the degree of satisfaction. The strategy of internal marketing derives its importance from the importance of the process of interaction between the employees of the organization and customers, especially in the field of services. The production and consumption processes coincide, and the human element controls service delivery process. Both are involved in the organization and customers in the production of the same service (Vandermerue, 1990). Educational organizations can adopt the concept of internal marketing because it enables them to reach their customers (external customers) better through internal customers (employees of the organization) by improving the work environment within them and improve their relations with employees (Wong \& Perry, 1991).

\section{Research problem}

In spite of the interest of Prince Sattam bin Abdul Aziz University in internal marketing, the actual implementation of the components of internal marketing within this university, is still below the required level, and the degree of staffs' satisfaction differs from the internal marketing procedures and policies applied by the university, which requires studying and analyzing the policies and procedures of the internal marketing followed at the university and the extent of its employees' satisfaction.

The research problem can be expressed through the following questions

- The extent of the application of Prince Sattam bin Abdul Aziz University policies and procedures related to the various components of internal marketing,

- How satisfied are the employees at Prince Sattam bin Abdul Aziz University about the policies and procedures of internal marketing in it?

- Is there any relationship between the extent of the application of Prince Sattam bin Abdul Aziz University's policies and procedures related to the various components of internal marketing and the degree of employees' satisfaction in this institution?

- How to activate the internal marketing activity at Prince Sattam bin Abdul Aziz University in a way that achieves its employees' satisfaction and contributes to improve their performance level?

\subsection{Research Objectives}

This study aims at

- Identifying the concept and characteristics of internal marketing at Prince Sattam bin Abdul Aziz University and its importance in enhancing its ability to market its educational products and services and enhance their market competitiveness.

- Identifying the most prominent policies and procedures of internal marketing at Prince Sattam bin Abdul Aziz University.

- Studying and analyzing the employees' opinions of Prince Sattam bin Abdul Aziz University about the extent of their application to various internal marketing policies and procedures and their satisfaction with them.

- Determining the relationship between internal marketing policies and the procedures applied in Prince Sattam bin Abdul Aziz University and the degree of its employees' satisfaction.

\subsection{Research Importance}

The importance of this research reflects the importance of effective application of various internal marketing policies and procedures at Prince Sattam bin Abdulaziz University and its role in achieving its employees' satisfaction and thus improve the level of performance of customer service, which is reflected in achieving quality performance and enhances its competitive position in the market.

Also, the importance of this study comes from being one of the first studies to address the concept, policies and procedures of internal marketing at Prince Sattam bin Abdul Aziz University and its relationship to the level of employees' satisfaction.

\subsection{Research hypotheses}

Based on the study problem, questions and objectives, the following hypotheses were formulated: 
First hypothesis

There is no statistically significant relationship between the extent of the application of Prince Sattam bin Abdul Aziz University to various internal marketing policies and procedures and the degree of employees' satisfaction.

The following branches emerge from this assumption:

- There is no statistically significant relationship between the extent of application at Prince Sattam bin Abdul Aziz University of effective policies and procedures in clarifying the roles of work among its employees and the satisfaction of its employees.

- There is no statistically significant relationship between Prince Sattam bin Abdul Aziz University for effective policies and procedures in training and developing the skills of its employees and the satisfaction of its employees.

- There is no statistically significant relationship between the extent of the application of Prince Sattam bin Abdul Aziz University to effective policies and procedures in motivating and rewarding its employees and the employees' satisfaction.

- There is no statistically significant relationship between the extent to which Prince Sattam bin Abdulaziz University has applied effective policies and procedures in enhancing relations between its employees and the satisfaction of its employees.

- There is no statistically significant relationship between the extent of the application of Prince Sattam bin Abdul Aziz University to effective policies and procedures in communications within the institution and employees' satisfaction.

- There is no statistically significant relationship between the extent of the application of Prince Sattam bin Abdul Aziz University policies and procedures effective in enhancing the motivation of employees and how satisfied the employees are.

- There is no statistically significant relationship between the support of senior management at Prince Sattam bin Abdul Aziz University for the policies and procedures of internal marketing and employees' satisfaction.

\section{Second hypothesis}

There are no statistically significant differences between the average satisfaction of employees at Prince Sattam bin Abdul Aziz University when applying this institution to the policies and procedures of internal marketing attributed to some of the demographic variables of these workers are gender, nationality, and educational qualification.

\subsection{Research Variables}

This research contains two types of variables

A-Independent variables: are represented in the dimensions or components of internal marketing.

- Clarifying the roles of work,

- Training and development of workers,

- Wages, rewards and incentives,

- Communication within the organization,

- Internal relations between employees,

- Enhancing motivation among employees,

- Supporting senior management of internal marketing policies and procedures.

\section{$B$ - Dependent variable}

This is represented by the degree of employees' satisfaction at Prince Sattam bin Abdul Aziz University with different internal marketing policies and procedures.

\subsection{Research Methodology}

The study used the descriptive analytical method and applied some questionnaire as a tool for collecting primary data in addition to collecting secondary data and information related to the theoretical framework and the literature of the study from its various sources of studies and previous research and published reports and statistics related to the subject of the study.

\subsection{Research population and Sample}

The research population included the employees of Prince Sattam bin Abdul Aziz University, which represented the general framework of the research population. In accordance with this framework, the research sample was determined and its size was (119) individuals who were selected spontaneously. 
To achieve the study objectives, the researcher used the questionnaire list as a tool to collect primary data from the vocabulary of the research sample and the questionnaire list consisted of two parts:

Part 1: Ensures data collection on demographic bases

The second part of the list includes 45 words to measure the study variables. Of these, 27 are used to measure policies and procedures related to internal marketing components and include phrases 1 to 27 .

The remaining 18 statements are related to the measurement of the dependent variable, which is the level of employees' satisfaction, including phrases 28 to 45 . The five alternatives were identified by Likert's five-scale scale (fully agree, agree, neutral, disagree, and disagree at all).

\subsection{Study Tool Validity and Reliability}

For the purposes of arbitration and to raise the level of the questionnaire list and to ensure that it achieves the goal for which it was set; it was reviewed and judged by ten academics and specialists in the preparation of studies at the university.

The tool was also applied to a Pilot Study sample of the actual sample population of twenty persons working at Prince Sattam bin Abdulaziz University. Moreover, some of their valuable observations were finalized in the questionnaire list.

The researcher verified the reliability of the tool by calculating the Cronbach Alpha coefficient to examine the internal consistency of the questionnaire paragraphs related to the independent variables and the dependent variable.

Table 1

Stability coefficient Alfa Kronbach for the study variables

\begin{tabular}{lc}
\hline Research variables & Alfa Cronbach coefficient \\
\hline Clarifying the roles of work for employees & 0.71 \\
Staff training and development & 0.74 \\
Wages, rewards and incentive policies & 0.87 \\
Internal relations between employees & 0.68 \\
Communication inside the organization & 0.84 \\
Employees' motivation & 0.76 \\
Senior management Support for internal marketing policies and procedures & 0.91 \\
Staff' satisfaction with internal marketing policies and procedures & 0.73 \\
The total value & 0.79 \\
\hline
\end{tabular}

\section{Literature Review}

A study by Richardson and Grant Robinson (1986) concluded that one of the effective methods to achieve excellence in the provision of banking service, is to improve the level of quality of services perceived by the end customer through the application of internal marketing programs either through the strategic or tactical level. The two researchers also believe that the practice of internal marketing at the strategic level aims to create an internal environment that supports the sense of consumers' awareness of the bank staff. The practice of internal marketing at the tactical level aims to increase employees' satisfaction by understanding what they are expected to do, accepting and supporting management policies, effective communication, providing information, training and motivating them. Thus, the availability of basic requirements for the application of internal marketing in the bank can lead to the promotion of the concept of consumer orientation, especially from front-line workers who deal more with customers, thus, improve the quality of service provided. Hogg et al. (1998) performed a study on the impact of internal marketing on the organizational culture of the organization. The study showed that despite the existence of a comprehensive and general concept among the organization's employees on the goals and values of the organization, they represent a neutral assessment of their staff. This means, in fact, that there are procedures related to internal marketing did not live up to the ambition of the staff which requires diagnosis and appropriate solutions. Alkhashab (2009) performed an investigation on the impact of some internal marketing procedures on the performance of workers, and aimed to show the impact of internal marketing procedures on the performance of workers in commercial banks in the city of Mosul. The study found the effect of internal marketing on staff performance and the existence of a non-significant correlation at the level of subvariables. The study found the effect of internal marketing procedures on the employees' performance and the presence of a weak and non-significant impact on the level of sub-variables on the procedures of dissemination of marketing information to employees on their performance.

Through reviewing the previous studies, it was noted that there are limited studies dealing with the impact of internal marketing on job satisfaction in educational organizations, especially Arabic studies. There is no study that deals with internal marketing and its relationship to workers' satisfaction in educational organizations in Saudi Arabia, which prompted the researcher to conduct this study. 


\section{Results of statistical analysis and study hypotheses:}

\subsection{First: Descriptive analysis of study variables}

The following are the descriptive analysis results of the study variables. These results include the arithmetic mean and the standard deflection of the answers of the sample of the research sample of employees at Prince Sattam bin Abdul Aziz University on the questionnaire statements related to the extent of their application of various internal marketing policies and procedures and the satisfaction of these workers with the application of their educational institution as follows;

1- The extent of the application of Prince Sattam bin Abdul Aziz University the internal marketing procedures

Table 2 shows the arithmetic mean and standard deviation of the answers of the research sample to the questionnaire question on the extent to which the university applies various policies and procedures related to internal marketing components.

Table 2

Arithmetic mean and standard deviation of the extent of the application of Prince Sattam bin Abdul Aziz University of various policies and procedures related to internal marketing components.

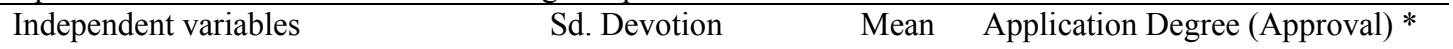

\begin{tabular}{|c|c|c|c|}
\hline Clarifying the roles of work for employees & 3.86 & 0.27 & High \\
\hline Staff training and development & 3.31 & 0.30 & Medium \\
\hline Wages, rewards and incentive policies & 2.02 & 0.26 & Low \\
\hline Internal relations between employees & 3.24 & 0.33 & Medium \\
\hline Communication inside the organization & 3.44 & 0.19 & Medium \\
\hline Employees' motivation & 3.43 & 0.25 & Low \\
\hline $\begin{array}{l}\text { Senior management Support for internal market- } \\
\text { ing policies and procedures }\end{array}$ & 2.12 & 0.31 & Medium \\
\hline Overall average & 3.15 & 0.29 & Medium \\
\hline
\end{tabular}

* (1 - less than 2.8) weak, (2.8 - less than 3.6) medium, (3.6-5) high

It is clear from the data of the table that the application of, Prince Sattam bin Abdul Aziz University, policies and procedures related to the various components of internal marketing was not promoted to the required level from the viewpoint of the research sample of workers. The average mean of the grand mean of the answers of the sample items to all the questionnaire statements related to the extent of the application of Prince Sattam bin Abdul Aziz University to various internal marketing policies and procedures in practice was 3.15) and a standard deviation was also equal to (1.44). We find that it falls between the degree of neutrality (3) and consent (4). Since the overall average has not reached 3.5, it remains close to neutral. This means that most of the University's internal marketing policies and procedures are applied to a moderate degree from the viewpoint of the research sample of staff. There are policies and procedures related to internal marketing applied less than the average, which can be seen from the table policies and procedures related to wages, incentives and rewards and enhance the motivation of employees. The mean averages of these elements are (2.02) and (2.43), respectively, which requires the departments of these institutions to diagnose and develop appropriate solutions to provide and apply them more effectively and meet the employees' aspirations in these institutions, since these elements of great importance in achieving employees' satisfaction and improve their job performance.

2- The extent of employees' satisfaction at Prince Sattam bin Abdul Aziz University - the research subject - on the internal marketing procedures

Table 3 shows the mean and standard deviation of the answers of the research sample of the employees of Prince Sattam bin Abdulaziz University to the questionnaire on determining their level of satisfaction with the application of various policies and procedures related to internal marketing components.

Table 3

Arithmetic mean and standard deviation of the satisfaction of employees at Prince Sattam bin Abdulaziz University on their application of various policies and procedures related to internal marketing components.

\begin{tabular}{|c|c|c|c|}
\hline Independent variables & Sd. Devotion & Mean & $\begin{array}{l}\text { Application Degree (Ap- } \\
\text { proval) * }\end{array}$ \\
\hline Employees' satisfaction with the procedures for clarifying the roles of the employees & 3.96 & 0.24 & High \\
\hline Employees' satisfaction with training and staff development procedures & 3.19 & 0.27 & Medium \\
\hline Employee satisfaction with wage, rewards and incentive policies & 1.77 & 0.21 & Low \\
\hline Employees' satisfaction with the procedures of internal relations between employees & 3.47 & 0.29 & Medium \\
\hline Staffs' satisfaction with communication procedures inside the organization & 3.50 & 0.28 & Medium \\
\hline Employees' satisfaction with employee motivation empowerment & 2.06 & 0.23 & Low \\
\hline $\begin{array}{l}\text { Employees' satisfaction with senior management support for internal marketing policies } \\
\text { and procedures. }\end{array}$ & 2.87 & 0.32 & Medium \\
\hline Overall average & 2.97 & 0.26 & Medium \\
\hline
\end{tabular}

* (1 - less than 2.8) weak, (2.8 - less than 3.6) medium, (3.6-5) high 
It is clear from the previous table that the level of employees' satisfaction at Prince Sattam bin Abdul Aziz University with most of the internal marketing policies and procedures applied in the university. It was a moderate average with a general arithmetic average of the respondents of the research sample of the employees on the questionnaire statements related to measuring their satisfaction with their internal marketing policies and procedures (2.97). The data of the table indicates that the degree of employees' satisfaction with a regard to internal marketing policies and procedures related to wages and incentives, as well as related to enhancing the employees' motivation was low with the average of the calculations respectively (1.77), (2.06). This is to some extent agrees with the averages of the views of these workers on the extent to which the university applies these various policies and procedures, as can be seen from the data in table (3). This emphasizes the need to be given to the University of Prince Sattam bin Abdul Aziz, the biggest importance of the provision and application of these policies and procedures in the form that achieves their employees' satisfaction.

\subsection{Second: Testing Results}

The following are the results of the study hypothesis tests according to the results of the statistical analysis of the questionnaire lists and the answers of the sample of the research sample on all terms related to the study variables.

\section{Testing the first hypothesis}

We have tested the validity of the first main hypothesis in this study, which states there is a statistically significant relationship between the extent of the application of Prince Sattam bin Abdul Aziz University to various internal marketing policies and procedures and the degree of employees' satisfaction and the seven sub-hypotheses related to this hypothesis related to the components of internal marketing. The Pearson correlation coefficient was used to determine the extent of a relationship between the independent study variables and the dependent variable, and the regression coefficient to determine the type and direction of this relationship and the level of significance. Table 4 shows the results of statistical analysis to test the validity of these hypotheses.

Table 4

Results of correlation and regression analysis between study variables.

\begin{tabular}{|c|c|c|c|c|c|c|}
\hline $\begin{array}{c}\text { Dependent } \\
\text { variable }\end{array}$ & Independent variables & $\mathrm{r}$ & $\mathrm{B}$ & $R^{2}$ & $\mathrm{t}$ (value) & Sig. \\
\hline \multirow{7}{*}{$\begin{array}{l}\text { Degree } \\
\text { of employees' satis- } \\
\text { faction }\end{array}$} & Clarity of the roles of work among employees & $* 0.647$ & 0.37 & 0.181 & 3.53 & 0.006 \\
\hline & Staff development \& training & $* * 0.541$ & 0.32 & 0.158 & 3.61 & 0.009 \\
\hline & Wages, incentives and rewards of employees & $* * 0.741$ & 0.44 & 0.102 & 4.32 & 0.000 \\
\hline & Relationship between staff & $* * 0.723$ & 0.29 & 0.145 & 3.94 & 0.002 \\
\hline & Communication inside the organization & $* * 0.586$ & 0.27 & 0.131 & 5.62 & 0.004 \\
\hline & Staff motivation & $* * 0.715$ & 0.42 & 0.112 & 4.17 & 0.001 \\
\hline & $\begin{array}{l}\text { Support and awareness of senior management of the im- } \\
\text { portance of motivating employees }\end{array}$ & $* 0.693$ & 0.39 & 0.063 & 3.78 & 0.003 \\
\hline
\end{tabular}

* Significant correlation at the level of significance 0.05

** Significant correlation at the level of significance 0.01

Table 4 shows the following:

- There is a positive and statistically significant correlation between the independent variable (clarity of roles of employees) and the dependent variable (level of employees' satisfaction). The correlation coefficient was (0.647) which indicates that the relationship between the clarity of the work roles of employees and their level of satisfaction with it is a direct relationship and that the strength of this relationship is 0.647 which is significant at a significant level of 0.05 . The regression coefficient was $\mathrm{B}=0.37$, which means that the relationship between the two variables is direct. This means that increasing the interest of Prince Sattam bin Abdul Aziz University in the application of policies and procedures related to clarifying the roles of work for employees leads to increase the level of employees' satisfaction. The value of the test $(\mathrm{t})=3.53$, which is significant at a level less than 0.05 . This confirms and supports the validity of this hypothesis, i.e. there is a positive correlation statistically significant between the clarity of the roles of work among employees and their level of job satisfaction. The coefficient of determination $\left(R^{2}\right)$ indicates that the independent variable (clarity of the roles of employees) explains $18 \%$ of the dependent variable, the level of employees' satisfaction. According to the above, it is clear that the imposition of nullity is not proven (sub-first imposition) which states there is no statistically significant relationship between the extent of the application of Prince Sattam bin Abdul Aziz University internal marketing policies and procedures related to clarifying the roles of work of its employees and the level of its employees' satisfaction, and therefore accept the alternative hypothesis which provides for a statistically significant relationship between variables.

- There is a positive correlation of statistically significant and medium between the independent variable (staff development and training) and the dependent variable (level of employee satisfaction). The correlation coefficient was (0.541), which indicates that the relationship between the development and training of employees' level of satisfaction is direct and that the strength of this relationship is (0.541) which is significant at the level of significance less than 0.05 . Regression coefficient B $=0.32$, which means that the relationship between the two variables is a direct relationship, in the sense that increasing the interest of Prince Sattam bin Abdul Aziz University in the application of policies and procedures related to the development and training of staff leads to increase the level of employees' satisfaction. The value of test $(\mathrm{t})=3.61$, which is significant at a level less than 0.05 . This confirms and supports the validity of this hypothesis, i.e. there is a positive correlation statistically 
significant between the development and training of employees and their level of job satisfaction. The coefficient of determination $\left(R^{2}\right)$ indicates that the independent variable (staff development and training) accounts for $15 \%$ of the dependent variable, the level of employees' satisfaction. According to the above, it is clear that there is no validity of imposition of nullity (sub-hypothesis I), which states there is no statistically significant relationship between the extent of Prince Sattam bin Abdul Aziz University's application of internal marketing policies and procedures related to the development and training of its employees and the level of its employees' satisfaction. Alternative hypothesis is, therefore, accepted which provides a statistically significant relationship between the two variables.

- The existence of a positive correlation of statistically significant and strong between the independent variable (wages, incentives and rewards of employees) and the dependent variable (level of employees' satisfaction), the correlation coefficient (0.742), which shows that the relationship between wages, incentives and rewards and employees' satisfaction level by a direct relationship. The strength of this relationship is 0.742 and is significant at a level of significance less than 0.05 . Regression coefficient $\mathrm{B}=0.44$, which means that the relationship between the two variables is a direct relationship, meaning that increasing the interest of Prince Sattam bin Abdul Aziz University in the application of policies and procedures related to wages, incentives and rewards of employees lead to an increase in the level of employees' satisfaction. The value of the test $(t)=4.32$, which is significant at a level less than 0.05 and this confirms and supports the validity of this hypothesis, that is, there is a positive correlation and statistically significant correlation between wages, incentives and rewards and the level of job satisfaction. The coefficient of determination $\left(R^{2}\right)$ indicates that the independent variable (wages, incentives and rewards of employees) accounts for $10 \%$ of the dependent variable, the level of employees' satisfaction. According to the above, it is clear that there is no validity of the imposition of non-imposition (sub-hypothesis III), which states there is no statistically significant relationship between the extent of the application of Prince Sattam bin Abdul Aziz University internal marketing policies and procedures related to wages, incentives and rewards of employees and the level of employees' satisfaction acceptance of the alternative hypothesis which provides for a statistically significant relationship between the two variables.

- The existence of a positive correlation of statistically significant and strong between the independent variable (internal relations between employees) and the dependent variable (level of employees' satisfaction), where the correlation coefficient is equal to 0.723 and it is significant at a level of significance $\alpha=0.05$. The regression coefficient was $B=0.29$, which means that the relationship between the two variables is a direct relationship. That means, increasing the interest of Prince Sattam bin Abdul Aziz University in the application of policies and procedures related to clarifying the roles of work for employees leads to increase the level of employees' satisfaction. The value of test $(\mathrm{t})=3.94$, which is significant at a level less than 0.05 . The value of the test $(\mathrm{t})=3.94$ which is significant at a level less than 0.05 confirms and supports the validity of this hypothesis, that is, there is a positive correlation statistically significant relationship between the internal relations between employees and their level of job satisfaction. The coefficient of determination $\left(R^{2}\right)$ indicates that the independent variable (internal relations between employees) accounts for $14 \%$ of the dependent variable, the level of employees' satisfaction.

According to the above, it is clear that there is no validity of the imposition of non-imposition (sub-hypothesis IV), which states that there is no statistically significant relationship between the extent of the application of Prince Sattam bin Abdul Aziz University - the subject of research - policies and procedures of internal marketing related to internal relations between employees and the level of employees' satisfaction. Alternative hypothesis is, therefore, accepted which provides a statistically significant relationship between the two variables.

- There was a positive correlation of statistically significant and medium between the independent variable (communications within Prince Sattam bin Abdul Aziz University) and the dependent variable (the level of employees' satisfaction), the correlation coefficient (0.586). It indicates that the relationship between the communications within the University of Prince Sattam bin Abdul Aziz and the level of satisfaction with them a direct relationship and that the strength of this relationship is 0.586 which is significant at a level of significance less than 0.05 . The regression coefficient was $\mathrm{B}=0.27$. This means that the relationship between the two variables is straightforward, in the sense that increasing the interest of Prince Sattam bin Abdulaziz University in the application of policies and procedures related to communications within the organization leads to an increase in the level of employees' satisfaction. The value of the test $(t)=5.62$. It is significant at a level less than 0.05 and this confirms and supports the validity of this hypothesis, i.e. there is a positive correlation and statistically significant relationship between the clarity of the roles of work among employees and their level of job satisfaction. The coefficient of determination $\left(R^{2}\right)$ indicates that the independent variable (communications within the organization) accounts for $13 \%$ of the dependent variable, the level of employees' satisfaction.

According to the above, it is clear that the imposition of nullity (sub-hypothesis V), which states there is statistically no significant relationship between the extent of the application of Prince Sattam bin Abdul Aziz University to internal marketing policies and procedures related to communications within the University of Prince Sattam bin Abdul Aziz and the level of employees' satisfaction and therefore accept the alternative hypothesis, which provides a statistically significant relationship between the two variables.

- The existence of a positive correlation of statistically significant and strong between the independent variable (motivation of employees) and the dependent variable (level of satisfaction of employees), where the correlation coefficient (0.715), which indicates that the relationship between motivation and satisfaction level of employees by a direct relationship and the strength of this relationship is 0.715 and it is significant when the level of significance is 0.05 . The regression coefficient was $\mathrm{B}=$ 
0.42. This means that the relationship between the two variables is direct, in the sense that increasing the interest of Prince Sattam bin Abdul Aziz University in the application of policies and procedures related to enhancing the motivation of its employees leads to increase these workers' level of satisfaction. The value of the test $(t)=4.17$ which is significant at a level less than 0.05 and this confirms and supports the validity of this hypothesis, that is, there is a positive correlation statistically significant correlation between enhancing motivation among employees and their level of job satisfaction. The coefficient of determination $\left(R^{2}\right)$ indicates that the independent variable (clarity of the roles of employees) explains about $11 \%$ of the dependent variable, the level of employees' satisfaction.

According to the above, it is clear that there is no validity of imposition of nullity (sub-hypothesis VI), which states that there is statistically no significant relationship between the extent of the application of Prince Sattam bin Abdul Aziz University policies and procedures of internal marketing. Therefore, an alternative hypothesis which provides for a statistically significant relationship between the two variables is accepted.

- There is a positive correlation of statistically significant and medium between the independent variable (support of senior management policies and procedures of internal marketing) and the dependent variable (level of satisfaction of employees). The correlation coefficient was (0.693). It indicates that the relationship between senior management support for internal marketing policies and procedures and their level of satisfaction with them is direct and that the strength of this relationship is 0.693 , which is significant at a level of significance less than 0.05 . The regression coefficient was $\mathrm{B}=0.39$. This means that the relationship between the two variables is direct, in the sense that increasing the interest and support of senior management of internal marketing policies and procedures leads to increased level of employees' satisfaction. The value of the test $(\mathrm{t})=3.78$ which is significant at a level less than 0.05 and this confirms and supports the validity of this hypothesis. That is, there is a statistically significant positive correlation between senior management support for internal marketing policies and procedures and their level of job satisfaction. The $\left(R^{2)}\right.$ determines that the independent variable (senior management support for internal marketing policies and procedures) accounts for $6 \%$ of the dependent variable, the level of employee satisfaction.

According to these results, it is clear that there is no validity of the imposition of nullity (sub-hypothesis VII), which states that there is no statistically significant relationship between the extent of senior management support for internal marketing policies and procedures and the level of satisfaction of employees.

According to the above it is clear that the imposition of nullity (the first main hypothesis) is not proven in this research, which states that there is no statistically significant relationship between the extent of the application of Prince Sattam bin Abdul Aziz University to the different policies and procedures of internal marketing and the degree of satisfaction of employees. It indicates the existence of a statistically significant relationship between the two variables internal marketing policies and procedures and employees' satisfaction at Prince Sattam bin Abdul Aziz University.

\section{Testing the second hypothesis}

The fourth hypothesis of the research hypotheses that there are no statistically significant differences between the average of employees' satisfaction at Prince Sattam bin Abdul Aziz University on the internal marketing policies and procedures applied in the university attributed to some demographic variables of these workers attributed to the variables of gender (male, female) nationality (Saudi, foreign) academic qualification (without qualification, basic, secondary, post-secondary diploma, university, high). Table 5 shows the results of this analysis: in order to test the validity of this hypothesis, one-way ANOVA analysis was used to determine the extent to which there are significant differences in the average degree of satisfaction of the vocabulary of the research sample of employees on the internal marketing policies and procedures applied at the university.

\section{Table 5}

Results of the analysis of the uneven variation of the average of employees' satisfaction on the internal marketing policies and procedures applied in Prince Sattam bin Abdulaziz University according to the demographic variables.

\begin{tabular}{|c|c|c|c|c|c|c|}
\hline $\begin{array}{c}\text { Variables } \\
\text { (Demographics) }\end{array}$ & S.O.V & df & SS & MSS & $\mathrm{f}$ (value) & Sig. \\
\hline Gender & $\begin{array}{l}\text { Between groups } \\
\text { Within groups } \\
\text { Total }\end{array}$ & 1 & $\begin{array}{c}264.46 \\
96.54\end{array}$ & $\begin{array}{c}63.59 \\
0.30\end{array}$ & 317.35 & 0.000 \\
\hline Nationality & $\begin{array}{l}\text { Between groups } \\
\text { Within groups } \\
\text { Total }\end{array}$ & 1 & $\begin{array}{l}116.86 \\
23.74\end{array}$ & $\begin{array}{c}56.09 \\
0.27\end{array}$ & 253.64 & 0.000 \\
\hline Qualification & $\begin{array}{l}\text { Between groups } \\
\text { Within groups } \\
\text { Total }\end{array}$ & 5 & $\begin{array}{c}221.31 \\
34.41\end{array}$ & $\begin{array}{c}93.91 \\
0.36\end{array}$ & 341.52 & 0.000 \\
\hline
\end{tabular}

* Significant correlation at the level of significance 0.05

** Significant correlation at the level of significance 0.01

It is clear from the Table 5 that there are statistically significant differences between the average of employees' satisfaction at Prince Sattam bin Abdulaziz University on the internal marketing policies and procedures applied at the level of significance (0.005). This is attributed to demographic variables related to gender, nationality and educational qualification. The calculated value of $F$ for each of these variables is greater than its tabular value (2.6) at the significance level (0.005). This means 
rejecting the null hypothesis, which states that there are statistically no significant differences between the average of employees' satisfaction at Prince Sattam bin Abdul Aziz University on the internal marketing policies and procedures applied in the university attributed to some demographic variables of these workers. which are; gender, nationality, academic qualification and acceptance of the alternative hypothesis which indicates a statistically significant relationship between the average of employees' satisfaction at Prince Sattam bin Abdul Aziz University about the internal marketing policies and procedures applied in the university attributed to the demographic variables: gender, nationality, scientific qualification at Indication Level (0.005).

\section{Conclusion}

Based on the results of the research, the researchers have proposed a set of recommendations that would increase the effectiveness of the application of various internal marketing policies and procedures at Prince Sattam bin Abdulaziz University, in a manner that meets the employees' aspirations and achieve their satisfaction. It should provide educational services working in the various departments of university to represent the first target market and the department should strive to achieve high degrees of job satisfaction to them. Therefore, the university administration should adopt the concept of internal marketing by designing and practicing different strategies, policies and programs directed to the needs and desires of its internal customers. It should design and describe effectively various functions, tasks and responsibilities of all employees in different disciplines, Prince Sattam bin Abdul Aziz University, in a manner that allows it to be filled with the right personnel and the need for clarity of the role required for each of its employees. It is better to give attention for planning, implementation and evaluation of training programs on an ongoing basis to develop the technical and behavioral skills of workers to increase the degree of reliability and response to them. Moreover, it is better to establish an effective, fair and flexible system of wages and incentives consistent with the nature of workers' tasks in different disciplines at the university and appropriate with the development of economic and living conditions in the society. It is good to increase the process of interaction between workers, which leads to create an atmosphere of happiness among them and work in the spirit of one team and the sense of the workers the importance of the role they play. It is necessary to do continuous evaluation of the level of application of various policies and procedures related to all dimensions of internal marketing from the viewpoint of the staff at Prince Sattam bin Abdul Aziz University to ensure their satisfaction.

\section{Acknowledgement}

The authors would like to thank the anonymous referees for constructive comments on earlier version of this paper.

\section{References}

Alkhashab, H. (2009). The impact of some internal marketing procedures on the performance of employees. Journal of Almowsail University, 2(24), 342-460.

Almaaghrabi, A. (2014). The quality of work life and its impact on the development of job dumping. Journal of Commerce Research, 2(15),73-89.

Berry, L. L. (1981). The employee as customer. Journal of Retail Banking, 3(1), 33-40.

Grönroos, C. (1990). Service management and marketing: Managing the moments of truth in service competition. JosseyBass.

Hadad, E. (2018). Test the validity of applying the internal marketing scale in the business environment. Jordanian Journal of Mannagement,4(18),34-49.

Hammed, S. (2015). The impact of internal marketing on the level of quality of service. Journal of Commerce Collage, 1(50), 243-255.

Harrell, G. D., \& Fors, M. F. (1995). Marketing services to satisfy internal customers. Logistics Information Management, 8(4), 22-27.

Hogg, G., Carter, S., \& Dunne, A. (1998). Investing in people: internal marketing and corporate culture. Journal of Marketing Management, 14(8), 879-895.

Richardson, B. A., \& Grant Robinson, C. (1986). The impact of internal marketing on customer service in a retail bank. International Journal of Bank Marketing, 4(5), 3-30.

Thabit, E. (2015). The quality of technical information services and their impact on sales representatives and sales performance. Scientific Economic Journal, 1(11),1-55.

Thabit, E. (2016). Analysis of the main determinants of internal marketing and external marketing and their impact on customer satisfaction. Journal of Commerce Collage, 1(56), 317-399.

Vandermerue, S. (1990). Customer drive corporations green program. Long Rang Planning, 23(6), 10-16.

William, G. (1990). Internal marketing and organizational behavior: A partnership in developing customer - conscious employees at every level. Journal of Business Research, 1(20) 63-70.

Wong, S. \& Perry, C. (1991). Customer services strategies in financial retailing. The International Journal of Bank Marketing, 1(19), 11-16. 
(C) 2020 by the authors; licensee Growing Science, Canada. This is an open access article distributed under the terms and conditions of the Creative Commons Attribution (CC-BY) license (http://creativecommons.org/licenses/by/4.0/). 